\title{
Client Independence Development Model in Wound TreatmentSelf-Based Treatment and Telenursing Nursing as Visible: A Study Literature (Paradigm of Nursing 21st century)
}

\author{
'Indah Nursanti , ${ }^{2}$ Moses Glorino Rumambo Pandin \\ Student at Faculty of Nursing, Airlangga University \\ ${ }^{2}$ Lecture at Faculty of Cultural Science, Airlangga University \\ Email: indah,nursanti-2020@,fkp.unair.ac.id
}

\begin{abstract}
Background: Nursing services provided by nurses are based on knowledge and competence in the field of nursing science developed in accordance with Client needs, scientific developments, and the demands of globalization. These health services include nursing services that are carried out responsibly, accountably, with quality, and safely by nurses who have obtained registration and permission to practice. Nursepreneur is innovation and courage to take risks and is ready to work hard to achieve goals with optimism. Which has important components namely: 1) quality, 2) role, 3) option and success. The post-pandemic new world, especially in the health care system, continues to grapple with the demands of costs to provide patient care and safety. By using the application of the nursing theory model. Purpose :. Assessing scientific studies on the application of evidence-based intervention in wound care using nursing theory, identifying the important role of telenursing in improving nursing services in Nerspreneurship, Method: literature study Conclusion: Telenursing in nursing focuses on providing nursing care through information technology, such as telephone, computers, and the Internet that can be used to improve treatment outcomes among older people, especially those with low literacy skills and low financial status (Esmaeilpour-BandBoni et al., 2020). The statement from the results of the study refutes that Telenursing is intended for patients who have higher education and middle and upper economic states.
\end{abstract}

Key words : Telenursing, Self Care Model, Nerspreneur

Refrenches : $(2018-2021)$

Coresponding Author:

Indah Nursanti,faculty of Nursing, Airlangga University, Surabaya, East Java, Indonesi;Email: indah,nursanti-2020@fkp.unair.ac.id

Background: The implementation of health development is realized through the provision of health services supported by health resources, both health workers and nonhealth workers. Nurses in implementing health services act as administrators of Nursing Practices, providers of Nursing care, counselors and counselors for clients, managers of nursing services, and nursing researchers. Nursing services provided by nurses are based on knowledge and competencies in the field of nursing science which are developed according to client needs, scientific developments, and globalization demands. These health services include nursing services that are carried out responsibly, accountably, with quality, and safely by nurses who have obtained registration and permission to practice. 
Nursing practice as a tangible manifestation of nursing services is carried out independently based on the delegation of authority, assignments under certain limitations, assignments in emergencies, or collaboration (Discussion of Nursing Law No. 36 of 2014).

Nurse is someone who has passed higher Level education in Nursing, both at home and abroad, who is recognized by the Government in accordance with the provisions of the Legislation. Nursing is the activity of providing care to individuals, families, groups or communities, both in sickness and in health. Nursing service is a form of professional service that is an integral part of health services based on Nursing knowledge and tips for individuals, families, groups or communities, both healthy and sick. Nursing Practice is a service provided by nurses in the form of Nursing Care (Discussion of Nursing Law No. 36 of 2014).

The number of nurses in Indonesia as of 2 September 2019 from the online database of SIMK nurses was 532,400 people who had been registered by the PPNI (Indonesian National Nurses Association). Of the total number of health workers in Indonesia, 60\% are nursing staff with educational levels of D3, S1 Ners, Masters, and Doctoral degrees. Every year there are 100,000 new nurses per year, the distribution of which work as volunteers, honorary staff in hospitals, at health centers, and even work outside the health sector (PPNI, 2019). Not all nurses who pass each year can be absorbed in Puskesmas, Hospitals or Private Clinics. Some are even unemployed, run self-employment and work in other fields outside the nursing field.

Wound care practitioners spread throughout Indonesia, with 12,800 graduates in 2019, and 14,050 graduates who have attended wound care training (Wocare, 2020). Currently, the number of independent nursing practices in Indonesia with wound care services is 363 throughout Indonesia in 2019, and 413 in 2020. From this number, it was found that there were 40 people throughout Indonesia, who focused on carrying out the profession as a Nerspreneur without working at other agencies (June 2020 Questionaire data) and it is expected to increase by more than $10 \%$ in 2021 . However, all nurses cannot have the opportunity to become a Nerspreneur because requirements requirements that must be met. besides that, being a Nerspreneur is the interest and choice of the individual nurse it self.

Conceptually, Nerspreneurs are included in the career development of the roles and functions of nurses. Nursepreneur is a new term in popularizing entrepreneurship associated with nurses or the world of nursing. In other words, entrepreneur nurse nurses who work independently in providing nursing services include direct care, education, research, administrative or consulting in creating a business / business. Nursepreneur is innovation and courage to take risks and is ready to work hard to achieve goals with optimism. Which has important components, namely: 1) quality; by being a creative person and able to pour ideas from concept to reality who have knowledge of management, namely business planning strategies, marketing, management information systems, leadership and financial management. 2) Role; as someone who can organize and manage and handle a business that takes risks for profit. 3) Option and success; have 
the skills and knowledge that can be developed to become a successful nurse (Fundamental Of Nursing, Taylor, 2000). Even so, entrepreneurs actually have 3 opportunities in running entrepreneurship, namely; Service, Selling and Consulting, but unfortunately this is rarely realized by the nurses themselves, so there are not many who are interested in exercising their focus as a Nerspreneur.

The development of entrepreneurship in the field of specialization in health, especially nurses, in opening nursing services in the community is increasingly difficult. The number of nurse graduates also continues to increase, however, many graduates do not find jobs and their income is not comparable to the cost of nursing education. And on this issue, the perspective of nursing graduates needs to be changed, both Diploma and Bachelor regarding opportunities for nurses who have only focused on health and education services. It is hoped that wound care practitioners will be able to offer an independent service to the community so that they can increase their income by starting a business or entrepreneurship. One of the types of businesses a wound care practitioner can create is independent nursing practice, care product development, home care or telenursing. (Sahputra \& Berlianto, 2021)

Service quality is the level of perfection of health services organized in accordance with the established code of ethics and service standards, so as to give rise to satisfaction for every patient (Ministry of Health in Muninjaya 2015). The quality of health services will be felt by its customers if the things that are delivered to the customers exceed expectations. The assessment of health service users will be directed at the substance of the message conveyed, the way it is delivered and the quality of services received by the users. Quality service is needed because it is the right of every customer, and can provide an opportunity to win the competition with other health service providers.

The COVID-19 pandemic has drastically disrupted everyday life. For several months now, the movement of people has been restricted, some businesses have been forced to close and the health system has been granted conditional freedom to provide services. Efforts to tackle the booming economic crisis, ranging from the design of personal protective equipment (PPE) and self-made ventilators, to procuring materials and supplies from the non-medical industry, have turned individuals into problem solvers, innovators and entrepreneurs. Top-down government initiatives to spur innovation center on the financial incentives of existing entities and businesses to provide essential equipment and supplies, or to reuse existing infrastructure for new use cases. However, how do we foster an ecosystem that combines top-down with grassroots innovation and drives the current recession of economic growth. This includes entrepreneurship run by nurses.

The new world after the COVID-19 pandemic, especially in the health care system, continues to grapple with the demands of costs to provide patient services and safety. Not only are the procedures and treatments becoming more complex and advanced but the expectations of patients, families and society in general are becoming higher. The trend and need for wound care centers will increase, because the two main contributors to the increase in the prevalence of diseases such as diabetes mellitus (DM) 
and the rapid growth of technology and medical care. It is estimated that 400 million people will suffer from diabetes in 2025 with a rapid increase in Asia, Africa and South America with an estimated $25 \%$ of them will suffer from diabetic foot ulcers (DFU) which require wound care(Gitarja \& Hurtado, n.d.)

Nursing interventions for patients in certain conditions must be given with a focus as support to improve the ability to manage diseases in everyday life.Clinical nurses must provide self-management support into something useful and structured (Hellqvist, 2021) The COVID-19 pandemic has put conditions around the world at the forefront of politics. difficult decisions made every day to manage in the near future with threats and how to determine how to inform the public about what happened.

(Mahendradhata \& Kalbarczyk, 2021). Most patients have significant co-morbidities and these conditions require a combination of strategies such as postoperative patients. However, with the criteria for using absorbable sutures, cyanoacrylate glue and restraint devices provide an excellent solution for easier post-surgical management and can provide self-care interventions. Despite the fact that it is possible for patients to need personal assistance because of their limited mental potential and skills, due to the condition of Covid 19, it would be appropriate in current circumstances to reduce the risk of transmission by choosing home management.(Verdura et al., 2021).

These situations and conditions require innovative and creative responses for a nurse to get opportunities and challenges in providing (Future Skills \& Industrial needs), (Be Entrepreneur), answering challenges as a nurse who continues to survive (Generation Era), following technological developments (We Are Trully in Digital Era), by strengthening the Internal Capability of Institution and regulations from (Indonesian Regulation on Nursing Profession \& Others).

One of the biggest challenges faced by nurses and other health professionals is whether they are able to provide care to patients with acute life-threatening illnesses, chronic conditions, or patients who are trying to stay healthy by taking preventative measures is finding the key to human motivation themselves.(M. J. Smith \& Patricia R. Liehr, 2018). Some of the theoretical concepts in the application of nursing care in this paper are the development of theoretical models from several studies that have been proven to be of benefit to nursing services in Indonesia.

\section{THEORITICAL CONTEXT :}

The study of this article covers what elements one wants to know (ontology), how to obtain knowledge (epistemology) and what the value of this knowledge is to humans (axiology).

The first theoretical concept used is an understanding of Orem's theoretical concepts, which focuses on health problems, namely self-care; which are universal, developmental requirements and health deviations; self-care activities as well as selfcare deficits, where several categories that can be included in the inclusion for this paper are not having ineffective airway cleaning problems that require suctioning management, have sufficient immobility, risk or impaired skin integrity in the healing 
process, risk of infection low, good peripheral tissue perfusion, effective thermoregulation, and effective health maintenance(Nascimento et al., 2021).

The second theoretical concept is Imogene King's interpersonal theory which explains that interpersonal relationships in the provision of nursing care are defined as interactions between two or more people by communicating with each other, then there is value and energy transferred from their role in society. Continuous interactions, ranging from low to high effectiveness ratios in nursing care. The essence of subjectivity demands seeking support for its evaluation. According to King Nursing is an observable behavior that is found in the health care system in society. The goal of nursing is to help individuals maintain their health so that they can function in their roles. Nursing is a process of action, reaction, and interpersonal transactions. The perceptions of a nurse and a patient influence interpersonal processes. Concepts relevant to interpersonal systems are interaction, communication, transactions, roles and stress(Borges et al., 2018). existing service models in nursing is the Transformational service model as a service at the highest level which is expected to be able to change the character of the customer because it is able to provide solutions to customer problems. Not only raises the feeling of Exciting as the goal, but more than Transformational service that wants to bring awareness to customers (Vicar \& Program, 2018).

The SERVQUAL (Service Quality) model is a tool to measure service quality superior service includes several aspects, including the ability in terms of physical appearance (tangibles), the ability to provide reliable and accurate services (realibility), the willingness to help customers and provide the best possible service (responsiveness). ), knowledge and kindness of employees to provide trust and confidence (assurance) as well as care and attention to customers individually (empathy). (Shengjin \& Jichuan, 2021). in providing nursing services, the quality of care is also needed which is considered very important with the health care system in the structure, process, and measurement results of the quality of nursing services that have been implemented by focusing on service assessment by determining how well it fulfills expectations with the concept of quality service quality.(Lu et al., 2020). Providing safety strategy planning, a manager must also demonstrate entrepreneurial behavior in the form of transformational leadership to modify the work environment in creating a better defense to prevent adverse events, especially in the care services that can be provided by a nurse.(Boamah, 2018). This is in order to support the concept that patients who are capable of self-care do need more confidence and energy when they return home and treat their themselves compared to those who remain dependent on direct care from nursing professionals.(Wang et al., 2021)

AIM :

The literature study aims to assess scientific studies on the application of evidence-based intervention in wound care using nursing theory, identify the important role of telenursing in improving nursing services in Nerspreneurship, as well as provide empowerment solutions that lead to entrepreneurship in nursing in today's global context with the conditions of the Covid Pandemic 19. 


\section{METHOD :}

The method used in this research is literature study by carrying out a series of activities with the method of collecting library data, reading and taking notes and processing the research material into an article.

\section{STUDY PROTOCOL;}

Guidelines for the quality of articles with the PRISMA table, to determine the quality of articles according to the theme. Article Search Strategy Articles were obtained by searching on 2 electronic databases, namely SCOPUS and Science Direct. The keywords used according to the chosen theme are adjusted to the Title of the Article.

\section{INCLUSION CRITERIA :}

The criteria for the inclusion of articles on phenomena related to the title, define: the population of interest, namely care that is carried out independently at home, regardless of geographical location with interesting phenomena, using implementation science in nursing care provided and results adjusted to theory, model, and framework work used to inform research; related effects; and factors that help or hinder implementation.(Dadich et al., 2021). Journal topics published in 2017 to 2021,: writings included in empirical research, using full names and in English and

RESULT: PRISMA, with study eligibility from title, abstract, methodology, results and full text.

From the number of journals as many as 30 which were used as sources of articles in this study literature, the value of scientific studies about the application of evidence-based intervention in wound care by using the development of nursing theory models in Nerspreneur services with the Covid 19 situation by sticking to the principle of service quality standards.

\section{DISCUSSION:}

The most common problem in wound care is diabetic foot with complications that increase with complexity, frequency or recurrent events and the cost is not cheap. Therefore we need application and self-management strategies to be able to reduce the risk of individuals with foot complications. The intervention given must be clear in type, scope and reference literature that supports self-management of patients with independence. This review covers the objectives of i) identifying actions in selfmanagement and avoiding risky behavior as a strategy in giving intervention, ii) mapping theoretical functions through this behavior change with good effect interventions, iii) presenting gaps in research(Paton et al., 2021). From another point of view in this article, the safety aspect is a very important part of all health management planning. Patient care pathways should be a central part of planning how 
e-Health solutions are integrated into current clinical practice. Professional teams are an important aspect of providing optimal care for patients, as many types of expertise are required to ensure proper treatment with a starting point for each patient's specific needs. The potential benefits of e-Health technology in wound care, and the possible obstacles to its application require a good strategy as a good recommendation in a good implementation process and support the involvement of wound care professionals in Nerspreneurship.

From another point of view in this article, the safety aspect is a very important part of all health management planning. Patient care pathways should be a central part of planning how e-Health solutions are integrated into current clinical practice. Professional teams are an important aspect of providing optimal care for patients, as many types of expertise are required to ensure proper treatment with a starting point for each patient's specific needs. The potential benefits of e-Health technology in wound care, and the possible obstacles to its application require a good strategy as a good recommendation in a good implementation process and support the involvement of wound care professionals in Nerspreneurship(Grisot et al., 2019). There are millions of patients around the world who need wound care products including selfadministered treatments in the hope of saving lives and changing lives. The foundation of knowledge necessary to develop such treatments is waiting to be discovered in current data. With the right analysis. The value of the RWDA (Real World Data Analysis) analysis currently in use may be applied in wound care in Indonesia. Especially during this ongoing COVID-19 crisis, RWDA offers the opportunity for important insights to become a meaningful platform for research, improvement of products and services. In addition, ongoing advances in Electronic Health Records and digital imaging will further facilitate the ability to apply, track and report real-world data. And now the RWDA on wound care is very valuable now and will likely balance its needs in the future (Madu, 2021).

Nerspreneurship services in nursing development in the 21 st century also require a good leadership spirit. Clinical leadership in integrated primary care requires deeper knowledge of leadership skills, as the implementation of integrated care with leadership support aimed at developing skills in self-care with management as a

nerspreneur (Ignatavicious et al., 2018).. A Nerspreneur as a Leader in his or her independent nursing practice plays an important role in implementing and sustaining changes in clinical practice, as evidence of strategies to involve problem solving and team communication (Lampman et al., 2021). including the development of telenursing-based innovations devoted to self-based care nursing model

The development of the practice of independence in Nerspreneurship that uses telenursing does require an emancipatory strategy to strengthen social protagonism. Nerpreneurs must always innovate and recycle in entrepreneurship related to providing nursing care with appreciation, recognition and collaborating with existing social workers then creating space as a socialization of experiences according to the expectations and perspectives of their clients (Borges et al., 2018). Practical guidance in care requires measures to be developed to capture a strong constellation of components integrated with quality guidance from the nurse itself.(A. B. Smith et al., 
2021). The provision of high quality self-care provided by nerspreneurs is an integral part of improving the health of the population and the sustainable development of the nation. safety is a major consideration in any system-level effort to provide self-care aimed at improving the health and well-being of the public population. Collaborative learning and interprofessional teamwork in an effort to reduce mortality and improve the health of the population is often referred to as the grand convergen (Health \& Journal, 2017). Notwithstanding, it is true that the conditions of self-reliant community interest in learning in low-income countries may be more challenging than in highincome countries which are a challenge for the provision of self-care by nurses themselves (Jansen et al., 2021).

\section{CONCLUSION:}

The development of a self-reliance model in wound care using a nursing theory model with telenursing applications in nerpreurship is an innovation from nursing that focuses on the service business as a social enterprise is an organization formed to solve social problems using a business model to support themselves financially. it is intended to help improve access to primary health care in low resource settings. Although currently social enterprises in health care have focused on high-income countries because of financial capacity, or on secondary and tertiary care in low- and middleincome countries, where common business models include different pricing to crosssubsidize populations low income .. The aim of this development is also to determine if the model is feasible and to identify general applicable patterns and characteristics (Lokman \& Chahine, 2020).

Nerspreneur development, which is a service innovation with a focus on the service business, does not see gender as the culprit. Even so, women have a better chance because this work does not tie into her role as mother, with its causal complexities, entrepreneurial cognition, norms, and financial regulatory abilities that identify the obstacles a woman actually faces in a more global and diverse context. At the same time, we aim to provide heterogeneous solutions that can lead to improvements the entrepreneurial level of women as a nurse. Notwithstanding, entrepreneurial cognition and high initial funding requirements play (Wu et al., 2019)

The practice of this Independence Model must still pay attention to the quality of health services and has become an important thing that is the demand of all parties, including people who are users of health professional services. because it's a problem The quality of health services should be a significant concern. Indeed, not all services provided can satisfy everyone. Therefore quality nursing services (SERVQUAL) to meet patient satisfaction are largely determined by the performance of the health care provider (Akob et al., 2021). The SERVQUAL approach always provides useful information with feedback by patients and their families for service quality. In many aspects, good performance is needed and felt by patients and their families (Lu et al., 2020)

The development of the Nursing Model in practice needs attention and training to become a nurse who is a solution to the problems of nursing services globally both during the Covid 19 pandemic and after this pandemic ends so that it becomes a new culture in providing self-care to patients provided by Nerspreneurs with constant 
reference to on referral services at the hospital. To reduce waste of resources providing training for the care workforce, and to improve the quality of available care. Hospitals can also use this theory as a reference and create a quality training and supportive environment to help nurse practitioners complete their training programs and improve the quality of care (Ting et al., 2021).

Self-care at home with High quality service delivery requires collaboration and mutual understanding among managers, employees, users, and policy makers of the entire health care system. Model development The concept of health care professionals' perceptions of quality outside the hospital setting should also include professional pride accompanied by professional competence with a patient-centered approach by being a factor in remedial activities and in daily practice.(Aase et al., 2021). Nurse as a care provider has the opportunity to make a difference in prevalence that occurs outside the acute and post-acute care setting, for example in the case of pressure injury (Singh \& Shoqirat, 2021)

The COVID-19 pandemic presents unique challenges in service provision in developing countries. Teleconsultation, telenursing services for outpatient treatment, follow-up and virtual teaching strategies related to surgical nursing, one of which is neurosurgery..(Dhandapani \& Dhandapani, 2021). Telenursing in nursing focuses on providing nursing care through information technology, such as telephones, computers, and the Internet that can be used to improve treatment outcomes among older people,

particularly those with low literacy skills and low financial status..(EsmaeilpourBandBoni et al., 2020). The statement from the results of the study refutes that Telenursing is intended for patients who have higher education and middle and upper economic status.

\section{REFRENCE}

1.Aase, I., Ree, E., Johannessen, T., Strømme, T., Ullebust, B., Holen-Rabbersvik, E., Thomsen, L. H., Schibevaag, L., van de Bovenkamp, H., \& Wiig, S. (2021). Talking about quality: how 'quality' is conceptualized in nursing homes and homecare. BMC Health Services Research, 21(1), 1-12. https://doi.org/10.1186/s12913-021-06104-0

2.Akob, M., Yantahin, M., Ilyas, G. B., Hala, Y., \& Putra, A. H. P. K. (2021). Element of Marketing: SERVQUAL Toward Patient Loyalty in the Private Hospital Sector. Journal of Asian Finance, Economics and Business, 8(1), 419-430. https://doi.org/10.13106/jafeb.2021.vol8.no1.419

3.Boamah, S. (2018). Linking Nurses' Clinical Leadership to Patient Care Quality: The Role of Transformational Leadership and Workplace Empowerment. The Canadian Journal of Nursing Research = Revue Canadienne de Recherche En Sciences Infirmieres, 50(1), 9-19. https://doi.org/10.1177/0844562117732490

4.Borges, J. W. P., Moreira, T. M. M., \& Andrade, D. F. de. (2018). Nursing Care Interpersonal Relationship Questionnaire: elaboration and validation. Revista LatinoAmericana de Enfermagem, 25, e2962. https://doi.org/10.1590/1518-8345.2128.2962 
5.Dadich, A., Piper, A., \& Coates, D. (2021). Implementation science in maternity care: a scoping review. Implementation Science, 16(1), 1-20.

https://doi.org/10.1186/s13012-021-01083-6

6.Dhandapani, M., \& Dhandapani, S. (2021). Challenges posed by COVID-19 and neurosurgical nursing strategies in developing countries. Surgical Neurology International, 11(441), 4-6. https://doi.org/10.25259/SNI_677_2020

7.Esmaeilpour-BandBoni, M., Gholami-Shilsar, F., \& Khanaki, K. (2020). The Effects of Telephone-Based Telenursing on Glycated Hemoglobin Among Older Adults With Type 2 Diabetes Mellitus: A Randomized Controlled Trial. Journal for Nurse Practitioners, 17(3), 305-309. https://doi.org/10.1016/j.nurpra.2020.09.015

8.Gitarja, W. S., \& Hurtado, J. M. (n.d.). The Impact of Clinical Leadership Competencies that Influence Wound Care Clinician for Managing Diabetic Foot Ulcer in Primary Health Care Services : A systematic literature review I. INTRODUCTION.

9.Grisot, M., Moltubakk Kempton, A., Hagen, L., \& Aanestad, M. (2019). Data-work for personalized care: Examining nurses' practices in remote monitoring of chronic patients. Health Informatics Journal, 25(3), 608-616.

https://doi.org/10.1177/1460458219833110

10.Health, M., \& Journal, R. (2017). l H ta en ea lth Re vi ew Jo ur na l l H ta en Re vi ew Jo. 0-14.

11.Hellqvist, C. (2021). Promoting self-care in nursing encounters with persons affected by long-term conditions - a proposed model to guide clinical care. International Journal of Environmental Research and Public Health, 18(5), 1-17. https://doi.org/10.3390/ijerph18052223

12.Ignatavicious, D. D., Workman, M. L., Rebar, C., \& Heimgartner, N. M. (2018). Medical-Surgical Nursing: Concepts for Interprofessional Collaborative Care. 1808.

13.Jansen, M., Lund, D. W., Baume, K., Lillyman, S., Rooney, K., \& Nielsen, D. S. (2021). International clinical placement - experiences of nursing students' cultural, personal and professional development; a qualitative study. Nurse Education in Practice, 51(February), 102987. https://doi.org/10.1016/j.nepr.2021.102987

14.Lampman, M. A., Chandrasekaran, A., Branda, M. E., Tumerman, M. D., Ward, P., Staats, B., Johnson, T., Giblon, R., Shah, N. D., \& Rushlow, D. R. (2021). Optimizing Huddle Engagement Through Leadership and Problem Solving Within Primary Care: Results from a Cluster-Randomized Trial. Journal of General Internal Medicine. https://doi.org/10.1007/s11606-020-06487-6

15.Lokman, L., \& Chahine, T. (2020). Business models for primary health care delivery in low and middle income countries: a scoping study of nine social entrepreneurs. 6, 1-12. https://doi.org/10.21203/rs.3.rs-35167/v1 
16.Lu, S. J., Kao, H. O., Chang, B. L., Gong, S. I., Liu, S. M., Ku, S. C., \& Jerng, J. S. (2020). Identification of quality gaps in healthcare services using the SERVQUAL instrument and importance-performance analysis in medical intensive care: A prospective study at a medical center in Taiwan. BMC Health Services Research, 20(1), 1-11. https://doi.org/10.1186/s12913-020-05764-8

17.Madu, T. (2021). Conducting meaningful real-world data analysis in wound care a guide. Journal of Wound Care, 30(2), 93-94.

https://doi.org/10.12968/jowc.2021.30.2.93

18.Mahendradhata, Y., \& Kalbarczyk, A. (2021). Prioritizing knowledge translation in low- and middle-income countries to support pandemic response and preparedness. Health Research Policy and Systems, 19(1), 10-12.

https://doi.org/10.1186/s12961-020-00670-1

19.Nascimento, T. F., Almeida, G. M. F. de, Bello, M. P., Silva, R. P. L. da, \& Fontes, C. M. B. (2021). Coronavirus infections: health care planning based on Orem's Nursing Theory. Revista Brasileira de Enfermagem, 74Suppl 1(Suppl 1), e20200281. https://doi.org/10.1590/0034-7167-2020-0281

20.Paton, J., Abey, S., Hendy, P., Williams, J., Collings, R., \& Callaghan, L. (2021). Behaviour change approaches for individuals with diabetes to improve foot selfmanagement: a scoping review. Journal of Foot and Ankle Research, 14(1), 1-14. https://doi.org/10.1186/s13047-020-00440-w

21.Sahputra, D., \& Berlianto, M. P. (2021). The impact of personality traits on entrepreneurial intentions of the Indonesian wound care clinicians. International Journal of Research in Business and Social Science (2147-4478), 10(1), 60-68. https://doi.org/10.20525/ijrbs.v10i1.1012

22.Shengjin, W., \& Jichuan, W. (2021). Service Quality Evaluation Method of City Shared Bicycles Based on SERVQUAL Model. E3S Web of Conferences, 236, 03022. https://doi.org/10.1051/e3sconf/202123603022

23.Singh, C., \& Shoqirat, N. (2021). Community-Acquired Pressure Injuries in the Acute Care Setting. Advances in Skin \& Wound Care, 34(3), 1-4.

https://doi.org/10.1097/01.ASW.0000732748.56041.cf

24.Smith, A. B., Umberfield, E., Granner, J. R., Harris, M., Liestenfeltz, B., Shuman, C., \& Smith, E. M. L. (2021). Development and preliminary testing of the collaboration for leadership and innovation in mentoring survey: An instrument of nursing PhD mentorship quality. Nurse Education Today, 98(December 2020), 104747. https://doi.org/10.1016/j.nedt.2021.104747

25.Smith, M. J., \& Patricia R. Liehr. (2018). Middle Range Theory for Nursing: Theory of Self-Care of Chronic Illness. In Middle Range Theory for Nursing.

26.Ting, Y. C., Chiang, C. Y., Lu, C. Y., \& Sun, F. K. (2021). Developing a theory to guide nurse practitioners to accomplish [a] training programme: A grounded 
theory study. Nurse Education Today, 99(8), 104814.

https://doi.org/10.1016/j.nedt.2021.104814

27.Verdura, V., Di Pace, B., Cagiano, L., \& Portincasa, A. (2021). Home wound management during the COVID-19 pandemic: The use of a novel adhesive retention suture. JAAD Case Reports, 9, 67-68. https://doi.org/10.1016/j.jdcr.2021.01.008

28.Vicar, M. L. A. Mac, \& Program, O. (2018). 高众 1 ，刘继安 2 ，陈健坤 3. 74(4), 55-61.

29.Wang, M., Lv, L., Yu, Z., Gao, L., Lu, Q., Ou, J., \& Luo, S. (2021). A crosssectional study of readiness for discharge, chronic illness resources and postdischarge outcomes in patients with diabetic foot ulcer. Nursing Open, December 2020, 1-10. https://doi.org/10.1002/nop2.813

30. Wu, J., Li, Y., \& Zhang, D. (2019). Identifying women's entrepreneurial barriers and empowering female entrepreneurship worldwide: a fuzzy-set QCA approach. International Entrepreneurship and Management Journal, 15(3), 905-928. https://doi.org/10.1007/s11365-019-00570-z 